\title{
Intercomparison of Water Vapor Data Measured with Lidar during IHOP_2002. Part II: Airborne-to-Airborne Systems
}

\author{
Andreas Behrendt, ${ }^{*}$ Volker Wulfmeyer, ${ }^{*}$ Christoph Kiemle, ${ }^{+}$Gerhard Ehret, ${ }^{+}$ \\ Cyrille Flamant, \# Thorsten Schaberl, * Hans-Stefan Bauer,* Susan Kooi,@ Syed Ismail, @ \\ Richard Ferrare, ${ }^{@}$ Edward V. Browell, ${ }^{@}$ AND David N. Whiteman $\&$ \\ *Institut für Physik und Meteorologie, Universität Hohenheim, Stuttgart, Germany \\ + Deutsches Zentrum für Luft- und Raumfahrt (DLR), Oberpfaffenhofen, Germany \\ \# CNRS Service Aéronomie, Université Pierre et Marie Curie, Paris, France

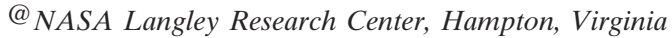 \\ \& Mesoscale Atmospheric Processes Branch, NASA GSFC, Greenbelt, Maryland
}

(Manuscript received 24 August 2005, in final form 6 December 2005)

\begin{abstract}
The dataset of the International $\mathrm{H}_{2} \mathrm{O}$ Project (IHOP_2002) gives the first opportunity for direct intercomparisons of airborne water vapor lidar systems and allows very important conclusions to be drawn for future field campaigns. Three airborne differential absorption lidar (DIAL) systems were operated simultaneously during some IHOP_2002 missions: the DIAL of Deutsches Zentrum für Luft- und Raumfahrt (DLR), the Lidar Atmospheric Sensing Experiment (LASE) of the National Aeronautics and Space Administration (NASA) Langley Research Center, and the Lidar Embarque pour l'etude des Aerosols et des Nuages de l'interaction Dynamique Rayonnement et du cycle de l'Eau (LEANDRE II) of the Centre National de la Recherche Scientifique (CNRS). Data of one formation flight with DLR DIAL and LEANDRE II were investigated, which consists of 54 independent profiles of the two instruments measured with 10-s temporal average. For the height range of 1.14-1.64 km above sea level, a bias of $(-0.41 \pm 0.16)$ $\mathrm{g} \mathrm{kg}^{-1}$ or $-7.9 \% \pm 3.1 \%$ was found for DLR DIAL compared to LEANDRE II (LEANDRE II drier) as well as root-mean-square (RMS) deviations of $(0.87 \pm 0.18) \mathrm{g} \mathrm{kg}^{-1}$ or $16.9 \% \pm 3.5 \%$. With these results, relative bias values of $-9.3 \%,-1.5 \%,+2.7 \%$, and $+8.1 \%$ result for LEANDRE II, DLR DIAL, the scanning Raman lidar (SRL), and LASE, respectively, using the mutual bias values determined in Part I for the latter three sensors. From the three possible profile-to-profile intercomparisons between DLR DIAL and LASE, one case cannot provide information on the system performances due to very large inhomogeneity of the atmospheric water vapor field, while one of the two remaining two cases showed a difference of $-4.6 \%$ in the height range of $1.4-3.0 \mathrm{~km}$ and the other of $-25 \%$ in $1.3-3.8 \mathrm{~km}$ (in both cases DLR DIAL was drier than LASE). The airborne-to-airborne comparisons showed that if airborne water vapor lidars are to be validated down to an accuracy of better than $5 \%$ in the lower troposphere, the atmospheric variability of water vapor has to be taken into account down to scales of less than a kilometer unless a sufficiently large number of intercomparison cases is available to derive statistically solid biases and RMS deviations. In conclusion, the overall biases between the water vapor data of all three airborne lidar systems operated during IHOP_2002 are smaller than $10 \%$ in the present stage of data evaluation, which confirms the previous estimates of the instrumental accuracies for all the systems.
\end{abstract}

\section{Introduction}

The International $\mathrm{H}_{2} \mathrm{O}$ Project (IHOP_2002) was performed in the Southern Great Plains of the United States during 13 May-25 June 2002 (Weckwerth et al.

Corresponding author address: Dr. Andreas Behrendt, Institut für Physik und Meteorologie, Universität Hohenheim, Stuttgart D-70593, Germany.

E-mail: behrendt@uni-hohenheim.de
2004). IHOP_2002 provides the largest set of state-ofthe-art water vapor lidar data collected so far in a field campaign. Three airborne lidar systems that measured humidity were operated simultaneously during certain IHOP_2002 missions. Before IHOP_2002, only single airborne water vapor lidar systems were employed in field campaigns. All these three systems used the water vapor differential absorption (DIAL) technique (Schotland 1966; Bösenberg 1998): the DIAL of the German Aerospace Center [Deutsches Zentrum für

DOI: 10.1175/JTECH1925.1

(C) 2007 American Meteorological Society 
Luft- und Raumfahrt (DLR)], which we hereafter refer to as DLR DIAL, the Lidar Atmospheric Sensing Experiment (LASE) of the National Aeronautics and Space Administration (NASA) Langley Research Center, and the Lidar Embarque pour l'etude des Aerosols et des Nuages, de l'interaction Dynamique-Rayonnement et du cycle de l'Eau (LEANDRE II) of the Centre National de la Recherche Scientifique (CNRS). The DIAL technique makes use of laser probing of the atmosphere at two wavelengths; one wavelength (socalled online) is located on a water vapor absorption line and the other wavelength (so-called offline) is positioned outside of the absorption band to act as a reference for the scattering and extinction properties of the atmosphere. The absolute humidity is determined from the difference of the slopes of the backscatter onand offline signals. To date, high-resolution water vapor DIAL measurements give us the best picture possible of the subscale variability of moisture and other atmospheric variables relevant (e.g., for the initiation of convection; Weckwerth et al. 2004). For these investigations, water vapor time-height cross sections or even water vapor fields measured with different aircrafts are of crucial interest.

The IHOP_2002 dataset provides the first opportunity for comparisons of water vapor DIAL systems and insight in their state-of-the-art performance and the corresponding specification of systematic and noise errors. The systematic as well as noise errors of DIAL systems have been investigated independently before (Bruneau et al. 2001a,b; Ismail and Browell 1989; Browell et al. 1997; Ferrare et al. 2002, 2004; Ehret et al. 1999; Poberaj et al. 2002; Wulfmeyer and Bösenberg 1998), but so far direct intercomparisons of water vapor DIAL systems are very rare. Before IHOP_2002, simultaneous measurements of water vapor DIAL systems have been performed only with LASE and a groundbased DIAL system (in 1995 during the LASE Validation Experiment; Browell et al. 1997) and in 2001 during the Atmospheric Radiation Measurement (ARM) First International Satellite Cloud Climatology Project (ISCCP) Regional Experiment (FIRE) Water Vapor Experiment (AFWEX; Ferrare et al. 2002, 2004). IHOP_2002 now provides the first opportunity for direct intercomparison of airborne DIAL systems. Therefore, IHOP_2002 data are also ideal for assessing the performance of future water vapor lidar instruments.

The benefits that spaceborne water vapor lidar instruments can offer compared to existing remote sensing data and techniques motivated the Water Vapor lidar Experiment in Space (WALES) project (European SpaceAgency 2001; Gérard et al. 2004; European SpaceAgency 2004) at the European Space Agency
(ESA). This intercomparison study was supported by the project "Measurement and Intercomparison of Active, Passive and In Situ Sensors During the International $\mathrm{H}_{2} \mathrm{O}$ Project for the Verification of the Specifications of the WALES Experiment" (Behrendt et al. 2004b).

Although an effort was made to obtain intercomparisons between various water vapor measuring systems, intercomparisons were not the main focus of the IHOP_2002 campaign and we performed a detailed and specific data analysis to find possible intercomparison cases of lidar systems in the IHOP_2002 dataset. For airborne-to-airborne DIAL intercomparisons, we found that no direct comparisons of the vertical data are available between LEANDRE II and LASE. A few profile-to-profile intercomparisons can be made with DLR DIAL and LASE data. Furthermore, a formation flight with small distances of $2-3 \mathrm{~km}$ between the lidar footprints was performed with DLR DIAL and LEANDRE II. Obviously, a formation flight is the most suitable configuration to compare the instrumental performances of airborne lidar systems because the sampled air masses are more similar than for crosstrack intercomparisons and a much larger number of comparison profiles can be collected in a short time period, which yields intercomparison results with a solid statistical basis.

In a companion paper (Behrendt et al. 2007, hereafter Part I), we have analyzed comparisons of LASE and DLR DIAL, respectively, with the scanning Raman lidar (SRL) of the NASA Goddard Space Flight Center (Whiteman et al. 2006a,b), which is a ground-based water vapor Raman lidar system. For the height interval of 1.3-3.8 km above sea level (ASL), we found mutual bias values of $-4.6 \%,-0.4 \%$, and $+5.0 \%$ for the humidity data of DLR DIAL, SRL, and of LASE, respectively. In this paper, we also discuss whether the airborne-to-airborne intercomparison results agree with these findings and derive the overall mean biases for all three airborne water vapor lidar instruments.

The structure of this paper is as follows. In section 2, we provide short descriptions of the DIAL systems operated during IHOP_2002. Because LEANDRE-II data were not included in the airborne-to-ground-based comparisons (Part I), we describe LEANDRE-II system characteristics in more detail here. Section 3 explains how the intercomparison cases were identified and the data were analyzed. Comparisons of the data measured with DLR DIAL and LEANDRE II during the formation flight are discussed in section 4, while three isolated comparison cases of DLR-DIAL and LASE data are investigated in section 5. In section 6, 
we discuss the results and give conclusions. Finally, the results are summarized in section 7 .

\section{Instrument descriptions}

\section{a. LEANDRE II}

During IHOP_2002, LEANDRE II (Bruneau et al. 1991) was mounted on the same aircraft, the P-3 of the Naval Research Laboratory (NRL), as the X-band radar, the Electra Doppler Radar (ELDORA) and was flown from 19 May to 25 June 2002. According to the type of mission, LEANDRE II performed either vertical or horizontal water vapor measurements. Not only was this the first time that a Doppler radar and water vapor DIAL were operated on the same aircraft, it was also the first time a water vapor DIAL was flown in horizontal-pointing mode. This combination enabled unprecedented insights in convection initiation processes (Murphy et al. 2006; Weckwerth et al. 2005). In this comparison study, we focus on vertical LEANDRE-II profiles (i.e., data taken during the atmospheric boundary layer, water vapor heterogeneity, and low-level jet missions; see Weckwerth et al. 2004). This is because all the other lidar instruments operated during IHOP_2002 measured vertical profiles only. A total of 24 missions were performed by LEANDRE II during IHOP_2002 amounting to a collection of $142 \mathrm{~h}$ of lidar data.

The details concerning the design of the LEANDREII system and the DIAL signal processing are given in Bruneau et al. (2001a,b) and are only briefly presented here. The transmitter of LEANDRE II is a flash-lamppumped alexandrite laser, which operates in a doublepulse, dual-wavelength mode in the 727-736-nm spectral domain. A pair of 50-mJ successive on- and offline pulses with an output line width of $2.410^{-2} \mathrm{~cm}^{-1}$ and a spectral purity typically larger than $99.99 \%$ are emitted at a $50-\mu$ s time interval with a repetition rate of $10 \mathrm{~Hz}$. The spectral positioning is controlled in real time on a shot-to-shot basis by a wavemeter with an absolute accuracy of $5 \times 10^{-3} \mathrm{~cm}^{-1}(\sim 140 \mathrm{MHz})$. The line narrowing necessary for laser emission with a narrow bandwidth is achieved using intracavity etalons. This technique results in a bandwidth of $560 \mathrm{MHz}$, so that corrections are applied if measurements are performed in the upper troposphere where the line widths of water vapor absorption lines become smaller. After a first reflection, the laser beam passes through a fivefold beam expander and is directed along the telescope's line of sight by a mirror placed in front of the telescope's secondary mirror (coaxial configuration). The output divergence of the laser can be adjusted from 0.5 to $3 \mathrm{mrad}$ to yield eye safety on the ground. A large steering mirror whose size covers the telescope aperture $(300 \mathrm{~mm})$ enables measurements at different angles. The receiver is a $30-\mathrm{cm}$ aperture telescope with a 3.5 -mrad field of view and a 1-nm filter bandwidth.

The characteristics of LEANDRE II were defined for measuring the water vapor mixing ratio with an instrumental systematic error of less than $2 \%$ and an accuracy better than $0.5 \mathrm{~g} \mathrm{~kg}^{-1}$ in the first $5 \mathrm{~km}$ of the atmosphere with a range resolution of $300 \mathrm{~m}$, an integration on 100 shots that corresponds to 10 -s operation time, and thus a horizontal resolution of approximately $1.5 \mathrm{~km}$ with the NRL P-3 flight speed of about 150 $\mathrm{m} \mathrm{s}^{-1}$. The overall accuracy excluding the uncertainty of line parameters was estimated to be $\sim 10 \%$ (Bruneau et al. 2001a,b). LEANDRE-II data with this resolution are used for the comparisons.

\section{b. DLR DIAL}

A short description of the DLR DIAL (Ehret et al. 1993, 1999; Poberaj et al. 2002) can be found in the companion paper (Part I ). The DLR DIAL was operated from the Falcon aircraft of DLR during IHOP_2002. For IHOP_2002, the systematic uncertainty of the DLR- DIAL water vapor data is estimated to be $4.2 \%(5.7 \%)$ in the near (far) range [i.e., at about $1.5 \mathrm{~km}(3.7 \mathrm{~km})$ below the aircraft]. These values include all potential systematic errors except the absorption cross-section uncertainty and contributions of the Rayleigh Doppler effect. The statistical uncertainties of the DLR-DIAL water vapor data of IHOP_2002 are small compared to the systematic uncertainties for all heights for the resolutions used in this study: the estimated statistical uncertainty for horizontal and vertical resolutions of $\sim 1.5 \mathrm{~km}$ (10-s flight time) and $195 \mathrm{~m}$, respectively, is $0.5 \%(3.4 \%)$ again for the near (far) range. This yields as overall accuracy of about $5 \%$ $(9 \%)$. It should be noted, however, that these values do not include the uncertainty of the absorption cross section of the water vapor line used during IHOP_2002. Unlike other error sources, this uncertainty introduces a constant relative bias onto all DLR-DIAL data, which, if large, should show up in a system intercomparison overview. For further details of how the uncertainties were estimated, see Behrendt et al. (2004a).

\section{c. LASE}

A short description of LASE can be found in the companion paper (Part I). During IHOP_2002, LASE was operated from the NASA DC-8 aircraft. The LASE water vapor profiles were retrieved using a vertical resolution of $330 \mathrm{~m}$ for altitudes above 330 $\mathrm{m}$ above ground level and a horizontal resolution of 
14-16 km along the flight direction (corresponding to a temporal averaging of $1 \mathrm{~min}$ ). Vertical and horizontal running averages were done on raw LASE data with $30-\mathrm{m}$ vertical and $6 \mathrm{~s}$ ( $1.4 \mathrm{~km}$ during IHOP_2002) horizontal resolutions. For DC-8 altitudes near $8 \mathrm{~km}$ a combination of the line center and sideline (at spectral separation of about +18 pm from the line center) positions were used to measure water vapor mixing ratios in the range of $0.1-1.0$ and 1.0 to $>15 \mathrm{~g} \mathrm{~kg}^{-1}$, respectively. The precision of water vapor measurements is estimated to be between $3 \%$ and $5 \%$ and total systematic errors are also estimated to be in the 3\%-5\% range (Ismail and Browell 1989) giving the overall accuracy of LASE measurements in the 5\%-10\% range. Previous water vapor comparisons have shown that the LASE water vapor mixing ratio measurements have an accuracy of better than $6 \%$ or $0.01 \mathrm{~g} \mathrm{~kg}^{-1}$, whichever is larger, across the troposphere (Browell et al. 1997; Ferrare et al. 2002, 2004). It was expected that the usual accuracy of the system also holds for the IHOP_2002 measurement data.

\section{Comparisons}

We tentatively set a $20-\mathrm{km}$ distance of the lidar footprints to search for intercomparison cases of the airborne DIAL systems. This is the same distance as used for the airborne to ground-based water vapor lidar comparisons (Part I ). Despite this modest limit, we found that only very few DIAL-to-DIAL intercomparisons are possible with the IHOP_2002 data: two independent profile-to-profile comparisons for DLR DIAL and LASE and one formation flight performed with DLR DIAL and LEANDRE II.

For these data, we calculated the bias (respectively, the difference in case of the single profile-to-profile comparisons between LASE and DLR DIAL) and root-mean-square (RMS) deviations of the water vapor mixing ratio data according to

$$
\begin{aligned}
\operatorname{Bias}_{i, \text { absolute }}\left(z_{1}, z_{2}\right) & =\frac{\sum_{z=z_{1}}^{z_{2}}\left[q_{1}(z)-q_{2}(z)\right]}{N_{z}}, \\
\operatorname{Bias}_{i, \text { relative }}\left(z_{1}, z_{2}\right) & =\frac{2 \sum_{z=z_{1}}^{z_{2}}\left[q_{1}(z)-q_{2}(z)\right]}{\sum_{z=z_{1}}^{z_{2}}\left[q_{1}(z)+q_{2}(z)\right]}, \\
\operatorname{RMS}_{i, \text { absolute }}\left(z_{1}, z_{2}\right) & =\sqrt{\frac{\sum_{z=z_{1}}^{z_{2}}\left[q_{1}(z)-q_{2}(z)\right]^{2}}{N_{z}}},
\end{aligned}
$$

$$
\mathrm{RMS}_{i, \text { relative }}\left(z_{1}, z_{2}\right)=\frac{\sqrt{\frac{\sum_{z=z_{1}}^{z_{2}}\left[q_{1}(z)-q_{2}(z)\right]^{2}}{N_{z}}}}{\frac{\sum_{z=z_{1}}^{z_{2}}\left[q_{1}(z)+q_{2}(z)\right]}{2 N_{z}}}
$$

where $i$ is an index denoting the intercomparison number; $q_{1}$ and $q_{2}$ are the water vapor mixing ratio values of the two sensors in the height $z ; z_{1}$ and $z_{2}$ are the lower and upper boundary, respectively, of the height interval considered; and $N_{z}$ is the number of data points for each sensor in this interval. Equations (1)-(4) were also used for the airborne-to-ground-based intercomparisons (Part I ). We decided to use also $500 \mathrm{~m}$ as length of the height intervals $\left(z_{1}, z_{2}\right)$ for the DIAL-to-DIAL intercomparisons because this is a good compromise for the effective resolution of the water vapor data to investigate height dependencies of the deviations. The bottom and top heights of the intercomparisons were adjusted for each comparison case.

For the formation flight of LEANDRE II and DLR DIAL, we then computed the mean bias and RMS deviation for each 500-m height interval and the total 2.5$\mathrm{km}$ interval of intercompared data according to

$$
\bar{X}\left(z_{1}, z_{2}\right)=\frac{\sum_{i} X_{i}\left(z_{1}, z_{2}\right)}{N_{i}},
$$

where $X$ denotes the RMS or bias in absolute or relative values, respectively, calculated with Eqs. (1)-(4), and $N_{i}$ is the number of possible intercomparison cases. Furthermore, we calculated the standard deviations of this mean.

Water vapor DIAL measures the water vapor number concentration $n_{\mathrm{H} 2 \mathrm{O}}$ (i.e., the number of $\mathrm{H}_{2} \mathrm{O}$ molecules per volume). The water vapor mixing ratio $q_{\mathrm{H} 2 \mathrm{O}}$ (in $\mathrm{kg} \mathrm{kg}^{-1}$ ) is then calculated with

$$
q_{\mathrm{H} 2 \mathrm{O}}=\left(\frac{p}{m_{\mathrm{H} 2 \mathrm{O}} n_{\mathrm{H} 2 \mathrm{O}} R T}-1.6078\right)^{-1} \mathrm{~kg} \mathrm{~kg}^{-1},
$$

where $m_{\mathrm{H} 2 \mathrm{O}}$ is the molecular mass of $\mathrm{H}_{2} \mathrm{O}, R=0.28704$ $\mathrm{J}(\mathrm{g} \mathrm{K})^{-1}$ is the special gas constant for dry air, $p$ is pressure, and $T$ is temperature (e.g., Warnecke 1997). Here $p$ and $T$ are needed as further input parameters and are usually taken from collocated radiosonde measurements or from models. We decided to compare water vapor mixing ratio data in this study because these 
are the data collected on the IHOP_2002 data server for atmospheric studies and it is important to assess their systematic and noise errors (see also Part I). It can be seen that an error of $1 \mathrm{~K}$ at a temperature of $250 \mathrm{~K}$ results in an error of $\sim 0.4 \%$ when deriving mixing ratio values from water vapor DIAL measurements. In future campaigns, this source of errors may be further reduced by simultaneous temperature measurements in the same air. Such measurements are also possible, for example, with lidar (Behrendt and Wulfmeyer 2003; Behrendt 2005).

\section{Formation flight of DLR DIAL and LEANDRE II}

Around universal time midnight [1900 local time (LT)] on 7-8 June 2002, the DLR Falcon and LEANDRE II performed a formation flight with minimum distances of the lidar footprints between 2 and 3 km (Fig. 1). Many features in the water vapor fields (Figs. 1d,e) coincide with features in the aerosol backscatter fields (Figs. 1f,g). Most clearly, this is seen at the top of the planetary boundary layer between about 2.0 and $2.5 \mathrm{~km}$ ASL, which is very similar in height for both the water vapor mixing ratio and the range-corrected aerosol backscatter signal.

The water vapor datasets of both DLR DIAL and LEANDRE II were calculated with a temporal resolution of $10 \mathrm{~s}$. It can be seen that the statistical noise in the LEANDRE-II data is larger than in the DLR-DIAL data for these resolutions, as it is expected from the instrumental parameters of the two systems. The structures of the measured water vapor fields are very similar. Both instruments detect a second dry layer centered $\sim 0.5 \mathrm{~km}$ above the top of the boundary layer that merges with the boundary layer toward the end of the formation flight around 0014 UTC. Furthermore, both instruments measure increased mixing ratio values also above $\sim 3.5 \mathrm{~km}$ ASL in the second half of the intercomparison period. Ground-level heights are increasing almost linearly from $\sim 0.2$ to $0.5 \mathrm{~km}$ ASL during the formation flight.

We compared those 10-s profiles of the two instruments for which the lidar footprint were closest (in space) because delays of a few seconds are less critical than spatial distances of a few kilometers (the aircraft velocities are much larger than the wind velocities here). A typical profile-to-profile intercomparison is shown in Fig. 1h. The heights of the transition zone at the boundary layer top, the two minima in 2.5 and 3.3 $\mathrm{km}$ ASL and the maximum in $2.8 \mathrm{~km}$ ASL coincide very well in the data of both instruments. Above the boundary layer, the humidity values differ in the minima and the maximum with less extreme values in the DLR-DIAL data, which could indicate different effective weighting functions. Inside the boundary layer (below $1.8 \mathrm{~km}$ ASL), the DLR-DIAL profile shows less variation with height than the LEANDRE-II data, which is probably caused by the large natural variability of atmospheric humidity in the boundary layer (e.g., Weckwerth et al. 1996; Kiemle et al. 1997; Couvreux et al. 2005).

A scatterplot as well as absolute and relative differences of all the 54 profiles are shown in Fig. 2. The data near the end of the first DLR-DIAL interval have been omitted as both aircrafts were changing the flight direction and the single profiles show consequently larger deviations here. Within the boundary layer, the measured water vapor mixing ratio values differ significantly for some of the profiles with deviations of up to -4 to $+1 \mathrm{~g} \mathrm{~kg}^{-1}$. This finding can be explained with the high resolution of the data: the horizontal averaging is significantly smaller than the distance of the flight tracks. Even though the formation flight was carried out in the local evening in the presence of a welldeveloped boundary layer, the water vapor mixing ratio within the boundary layer is by far not homogeneous as it can be seen in Figs. 1b,c. The variability- especially of the boundary layer-top height-is illustrated also clearly by the aerosol backscatter field of 1-s resolution ( $\sim 20$-m horizontal resolution) of DLR DIAL (Fig. 1f).

Bias and RMS deviations of the 54 profile-to-profile intercomparisons are shown in Figs. $2 \mathrm{~d}-\mathrm{g}$ for five consecutive height intervals of $500-\mathrm{m}$ window length between 1140 and $3640 \mathrm{~m}$ ASL. For all comparison cases, the bias values are mostly within -1.0 and $0.5 \mathrm{~g} \mathrm{~kg}^{-1}$ while larger deviations are found only for the lowest height interval where absolute humidity is largest (negative values of down to $-2.6 \mathrm{~g} \mathrm{~kg}^{-1}$ ) or the height interval which includes the boundary layer tops (positive values of up to $1.1 \mathrm{~g} \mathrm{~kg}^{-1}$ ). The relative bias values of all the cases are mostly within $-20 \%$ to $10 \%$ with larger relative differences for the highest interval with lowest absolute humidity. The RMS deviations are mostly $<1 \mathrm{~g} \mathrm{~kg}^{-1}$, while the relative RMS deviations are mostly all $<20 \%$ again with larger values found especially for the lowest and highest 500-m interval, respectively.

The mean profiles for the whole formation flight are shown in Fig. 3. The structure of the two mean profiles is very similar. The comparison of these profiles with high vertical resolutions show differences between -1.5 and $0.7 \mathrm{~g} \mathrm{~kg}^{-1}$ or $-27 \%$ and $10 \%$ (Figs. $3 \mathrm{~b}, \mathrm{c}$ ). While larger absolute differences are found at lower altitudes where the absolute humidity is higher, larger relative differences are found for higher altitudes. The RMS 

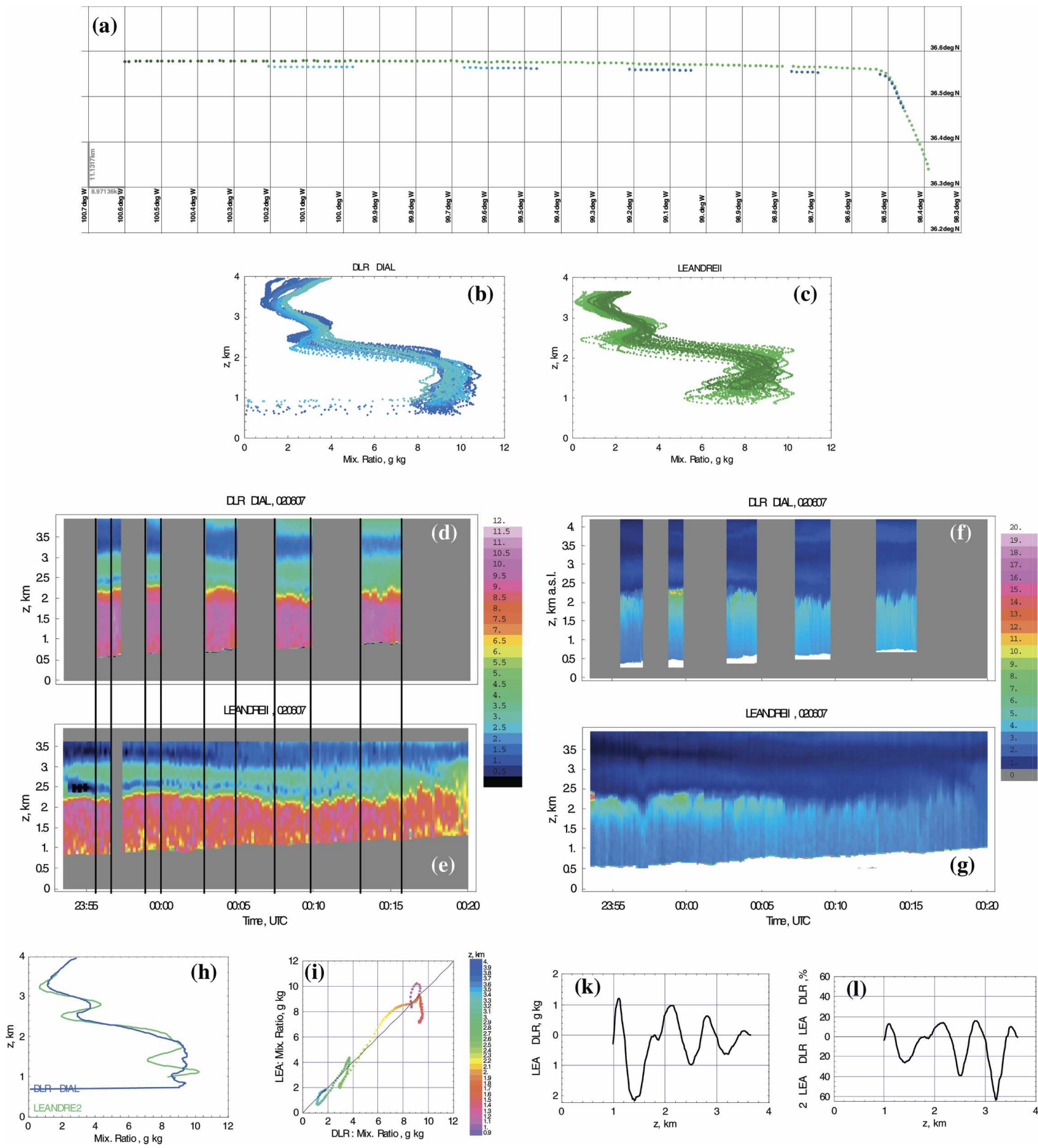

FIG. 1. (a) Flight tracks of the DLR Falcon and NRL P-3, which were the platforms for the DLR DIAL and LEANDRE II, respectively, during the formation flight between 2353:34 and 0020:00 UTC 7-8 Jun 2002. Green to gray dots mark the position of the NRL P-3 while blue to cyan dots mark the position of the DLR Falcon. (b), (c) Water vapor profiles measured simultaneously with DLR DIAL and LEANDRE II; color codes same as in (a). LEANDRE-II data are with a temporal resolution of $10 \mathrm{~s}$ and gliding vertical average of $300 \mathrm{~m}$ and DLR DIAL with the same temporal resolution of $10 \mathrm{~s}$ and an effective vertical resolution of $195 \mathrm{~m}$. (d), (e) Same as (b), (c) but as time-height plots. Gray areas mark data gaps. As the two aircrafts did not fly exactly synchronously in space and time, the time scale is for the LEANDRE-II and DLR-DIAL data measured at closest distance are plotted. (f), (g) Particle backscatter fields (range-corrected backscatter data of the offline signals in arbitrary units) measured during the formation flight. LEANDRE-II data are with resolutions of $10 \mathrm{~s}$ and $15 \mathrm{~m}$ and DLR DIAL with resolutions of $1 \mathrm{~s}$ and $15 \mathrm{~m}$. (h)-(l) Typical profile-toprofile intercomparison of DLR-DIAL and LEANDRE-II data. (h) DLR-DIAL and LEANDRE-II water vapor data measured on 8 Jun 2002 (case 13, first profile of third leg). (i) Scatterplot of the data for the heights indicated by the color coded bar. (k), (l) Absolute differences of the data (LEANDRE-II minus DLR-DIAL data) and relative deviations. The horizontal line at the bottom of the DLR-DIAL profile is an artifact due to masking of the data. 

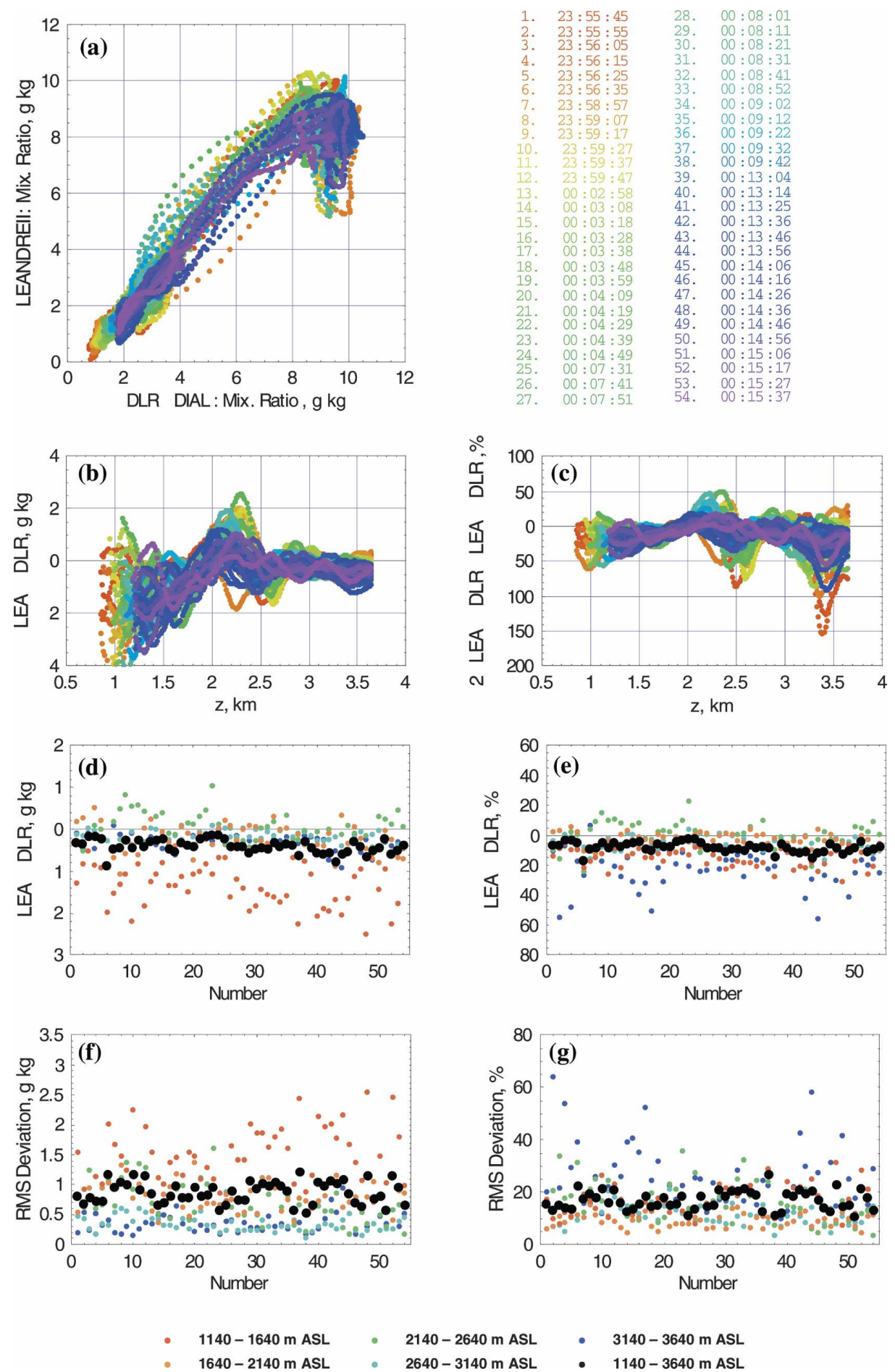

FIG. 2. (a) Scatterplot of water vapor mixing ratio measured with DLR DIAL and with LEANDRE II during the formation flight on 7-8 Jun 2002. The time of the profiles is color coded (see legend, UTC, with number of intercomparison case).(b), (c) Absolute and relative bias of the data (LEANDRE-II minus DLR-DIAL data). (d), (e) Bias (LEANDRE-II minus DLR-DIAL data) and (f), (g) RMS deviations for the 54 profile-to-profile intercomparisons between LEANDRE II and DLR DIAL. Different colors mark five consecutive height intervals of $500 \mathrm{~m}$ while black dots show bias and RMS deviations. 

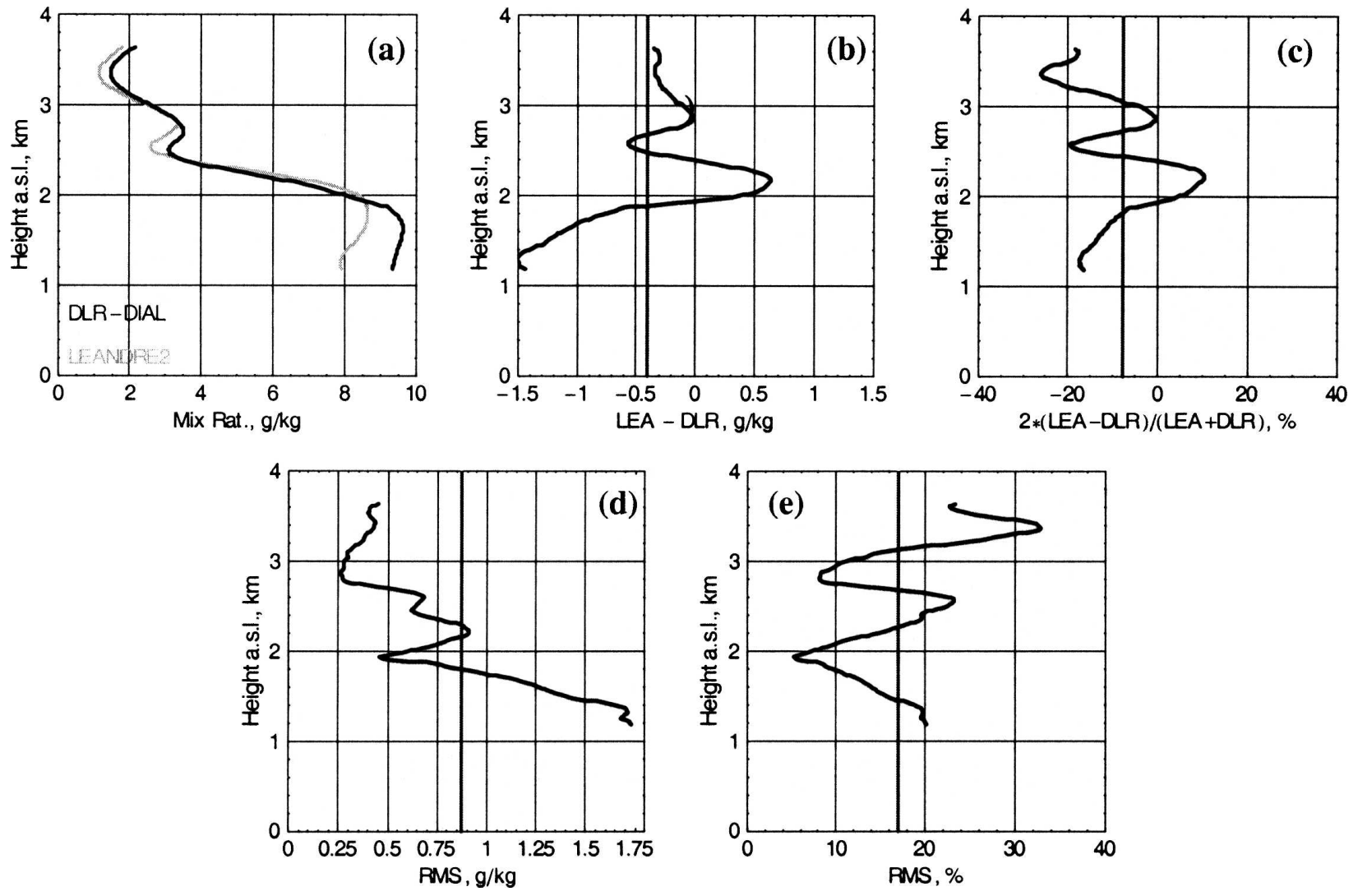

FIG. 3. Mean of all 54 compared profiles of the formation flight on 7-8 Jun 2002. (a) Mean water vapor mixing ratio measured with DLR DIAL (black) and with LEANDRE II (gray). (b), (c) Absolute and relative bias and (d), (e) absolute and relative RMS deviations. Mean values for the height range of 1140 and $3640 \mathrm{~m}$ ASL are shown with gray lines.

deviations (Figs. 3d,e) are between 0.25 and $1.7 \mathrm{~g} \mathrm{~kg}^{-1}$ $(5 \%-33 \%)$. Here the largest values are found again inside the boundary layer, which is caused by the large natural variability of the boundary layer humidity.

The results are summarized in Table 1 and Fig. 4 where the mean bias and RMS deviations for the 500-m intervals are shown with standard deviations. The bias is largest for the lowest interval with $-1.4 \pm 0.5 \mathrm{~g} \mathrm{~kg}^{-1}$, only $0.0 \pm 0.4 \mathrm{~g} \mathrm{~kg}^{-1}$ for the middle interval centered at $2.4 \mathrm{~km}$ ASL, and again larger for the highest interval with $-0.3 \pm 0.1 \mathrm{~g} \mathrm{~kg}^{-1}$. The same characteristic with lowest values for the center intervals is found for the relative bias. In contrast to this, the absolute RMS deviations show clearly a trend with altitude: the mean value is $1.5 \pm 0.5 \mathrm{~g} \mathrm{~kg}^{-1}$ for the lowest interval while it decreases to $0.4 \pm 0.2 \mathrm{~g} \mathrm{~kg}^{-1}$ for the highest interval. The relative RMS deviations show no trend with altitude due to the decrease of atmospheric humidity with height.

The mean results for the 54 comparison cases of the DLR DIAL and LEANDRE-II data in the $2.5-\mathrm{km}$ interval of 1140-3640 m ASL are

$$
\begin{aligned}
\overline{\operatorname{Bias}}_{\text {LEA-DLR,absolute }}= & (-0.41 \pm 0.16) \mathrm{g} \mathrm{kg}^{-1}, \\
& (\text { LEANDRE II drier }) \\
\overline{\mathrm{Bias}}_{\text {LEA-DLR,relative }}= & (-7.9 \pm 3.1) \%, \\
\overline{\mathrm{RMS}}_{\text {absolute }}= & (0.87 \pm 0.18) \mathrm{g} \mathrm{kg} \\
\overline{\mathrm{RMS}}_{\text {relative }}= & (16.9 \pm 3.5) \% .
\end{aligned}
$$

When instead of the mean of 500-m height intervals, the mean profiles for the whole formation flight (Fig.

TABLE 1. Mean differences between DLR DIAL and LEANDRE-II humidity data during the formation flight on 7-8 Jun 2002 in the height intervals indicated (with standard deviation of the differences).

\begin{tabular}{ccccc}
\hline $\begin{array}{c}\text { Height } \\
\text { interval } \\
(\mathrm{km} \mathrm{ASL})\end{array}$ & $\begin{array}{c}\text { Bias } \\
\left(\mathrm{g} \mathrm{kg}^{-1}\right)\end{array}$ & $\begin{array}{c}\text { Bias } \\
(\%)\end{array}$ & $\begin{array}{c}\text { RMS } \\
\left(\mathrm{g} \mathrm{kg}^{-1}\right)\end{array}$ & $\begin{array}{c}\text { RMS } \\
(\%)\end{array}$ \\
\hline $1.14-1.64$ & $-1.4 \pm 0.5$ & $-15 \pm 6$ & $1.5 \pm 0.5$ & $17 \pm 6$ \\
$1.64-2.14$ & $-0.2 \pm 0.4$ & $-3 \pm 4$ & $0.8 \pm 0.2$ & $9 \pm 3$ \\
$2.14-2.64$ & $0.0 \pm 0.4$ & $-1 \pm 9$ & $0.7 \pm 0.3$ & $17 \pm 8$ \\
$2.64-3.14$ & $-0.2 \pm 0.1$ & $-6 \pm 4$ & $0.3 \pm 0.1$ & $12 \pm 4$ \\
$3.14-3.64$ & $-0.3 \pm 0.1$ & $-21 \pm 13$ & $0.4 \pm 0.2$ & $25 \pm 12$ \\
$1.14-3.64$ & $-0.41 \pm 0.16$ & $-7.9 \pm 3.1$ & $0.87 \pm 0.18$ & $16.9 \pm 3.5$ \\
\hline
\end{tabular}



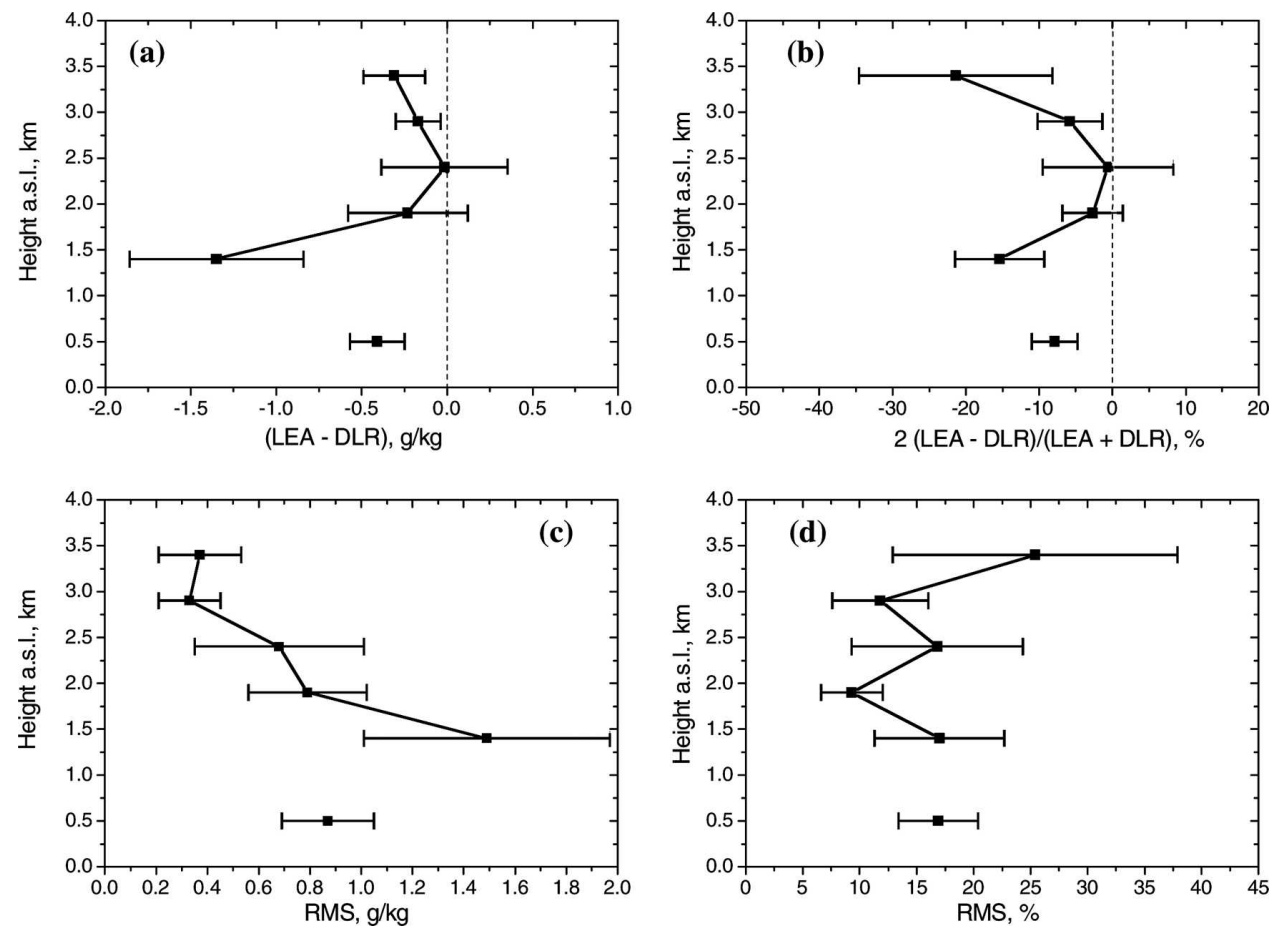

FIG. 4. Mean results for 500-m height intervals and 54 profile-to-profile intercomparisons of DLR DIAL and LEANDRE-II water vapor data during the formation flight on 7-8 Jun 2002. (Same data as listed in Table 1.) Error bars show the $\pm 1 \sigma$ standard deviation of the 54 comparison cases. The data points plotted at $0.5-\mathrm{km}$ height ASL show the mean values for the height interval of 1.14-3.64 km ASL.

3a) are calculated first and then bias and RMS deviation are computed for the mean profiles, we obtain the following values for the same $2.5-\mathrm{km}$ interval between 1140 and $3640 \mathrm{~m}$ ASL:

$\overline{\operatorname{Bias}}_{\text {LEA-DLR,absolute,av }}=-0.41 \mathrm{~g} \mathrm{~kg}^{-1}$, (LEANDRE II drier)

$$
\begin{aligned}
\overline{\operatorname{Bias}}_{\text {LEA-DLR,relative,av }} & =-7.7 \%, \\
\overline{\mathrm{RMS}}_{\text {absolute,av }} & =0.71 \mathrm{~g} \mathrm{~kg}^{-1}, \text { and } \\
\overline{\mathrm{RMS}}_{\text {relative,av }} & =13.9 \% .
\end{aligned}
$$

While we expect the same result for $\overline{\mathrm{Bias}}_{\text {LEA-DLR,absolute }}$ and $\overline{\mathrm{Bias}}_{\text {LEA-DLR,absolute, av }}$ because the averaging operators can be exchanged for the absolute bias, we find also that, in this case, the sequence of averaging operators applied to the intercomparison data has no large effect on the results of the relative bias and the relative and absolute RMS deviations. The RMS deviation in general quantifies an upper limit for the sum of the statistical uncertainties of the two compared instruments, systematic differences, and the natural variability of the atmosphere. Now the contribution of the statistical uncertainty becomes lower for $\overline{\mathrm{RMS}}_{\mathrm{absolute}, \mathrm{av}}$ and
$\overline{\mathrm{RMS}}_{\text {relative,av }}$ than for $\overline{\mathrm{RMS}}_{\text {absolute }}$ and $\overline{\mathrm{RMS}}_{\text {relative }}$ because averaged profiles are used for the former. Thus, we can conclude that, on the one hand, the intercomparisons confirm that the statistical uncertainties are already low for the high-resolution data of DLR DIAL and LEANDRE II. On the other hand, one can see that the differences are to a large degree due to natural differences and/or systematic deviations between the data. As the two aircrafts performed parallel flight tracks (minimum distances between about 2 and $3 \mathrm{~km}$ ) and the DIAL instruments could consequently not sample the same atmospheric air, a large portion of the RMS deviations in the measured data is likely due to natural variations of the water vapor field. Therefore, it is difficult to judge on systematic deviations by studying the results of these intercomparisons alone. The effect of natural differences could be minimized in future intercomparison studies by further reducing the distance of the locations where measurements are performed.

\section{Intercomparisons of DLR DIAL and LASE}

a. At 2109:40 UTC 24 May 2002

On 24 May 2002, the DLR Falcon and DC-8 flew near each other at 2109:40 UTC with a minimum dis- 

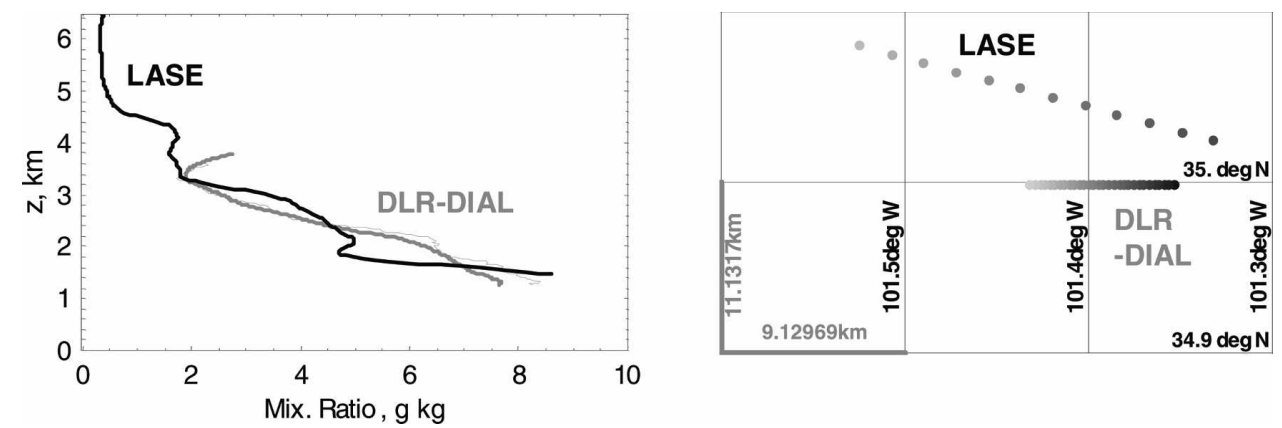

FIG. 5. (left) Measurements with DLR DIAL (gray; thick and thin for 60- and 2-s integration time, respectively) and LASE at 2109:40 UTC 24 May 2002 in the vicinity of a dryline. Because clearly different air masses were sampled, these data were not used to derive bias and RMS deviations of the sensors. (right) The 1-min flight tracks of DLR DIAL (black to gray) and LASE (black to gray) with 2109:40 UTC as the center time on 24 May 2002.

tance of $\sim 6 \mathrm{~km}$ of the lidar footprints. Water vapor measurements with DLR DIAL and LASE within \pm 30 $\mathrm{s}$ to the time of closest distance have been compared. From the water vapor and backscatter fields (not shown here) it can be seen that the location where the planes are closest at a given time is in this case very close to strong natural variations in the water vapor field ("dryline"). Thus, the clear difference in the vertical structure of the two measured profiles (Fig. 5) is caused by the large natural inhomogeneity of the water vapor field in this case. This example demonstrates very well the large natural variability that can be found in the atmospheric water vapor field even on a small scale.

\section{b. At 1420:51 UTC 9 June 2002}

On 9 June 2002, the DLR Falcon and DC-8 flew close to each other at 1420:51 UTC with a minimum distance of $\sim 1 \mathrm{~km}$ of the lidar footprints. The flight tracks of both aircrafts were parallel in the vicinity of the point of closest distance with opposite flight directions (Fig. 6): while the DLR Falcon's flight track was from the west to the east approximately on latitude $39.0^{\circ} \mathrm{N}$, the DC- 8 flew east to west about $1 \mathrm{~km}$ north of Falcon's flight track.

Water vapor measurements with DLR DIAL and LASE ( \pm 2 min to the meeting, center time of average interval) are displayed in Figs. 6i,k while the aerosol fields are shown in Figs. 6f,g. The agreement of the LASE measurement (water vapor mixing ratio of 2.678 $\mathrm{g} \mathrm{kg}^{-1}$ in $4837 \mathrm{~m} \mathrm{ASL}$ ) and Falcon in situ measurement $\left(2.74 \mathrm{~g} \mathrm{~kg}^{-1}\right.$ in $\left.4848 \mathrm{~m}\right)$ is excellent $(2.3 \%$ relative deviation). With 40-s averaging (gaps of the DLR DIAL data due to clouds are excluded), the Falcon flight path close to the point where the two aircrafts are closest is approximately as long as the 1-min LASE path. The differences between the DLR DIAL profiles with 10- and 40-s averaging are, however, small compared with the difference of the DLR DIAL data to the LASE data. Analyses of the intercomparison of the water vapor measurements of LASE and DLR DIAL closest to the meeting are shown in Figs. $6 \mathrm{~b}-\mathrm{d}$ and the results are summarized in Table 2. For all heights except in the lower part of the boundary layer and the upper heights of the compared data $(<1.5$ and $>3.5 \mathrm{~km}$ ASL, respectively), the differences between the datasets are approximately constant with about $20 \%$ higher values for the LASE data. For heights $<1.5$ and $>3.5 \mathrm{~km}$, differences up to $35 \%$ and $30 \%$, respectively, are seen.

DLR DIAL data closest to the two dropsondes launched close to the time of the intercomparison have also been investigated. However, the temporal and spatial gaps between DLR DIAL and dropsonde measurements are too large to judge on a possible bias of these DLR DIAL data. Thus, the reason for the nearly constant $20 \%$ bias between LASE and DLR DIAL profiles at $1.5-3.5 \mathrm{~km}$ (Figs. 6b-d) found in this comparison case remains open. We would like to point out that besides an instrumental bias between LASE and DLR-DIAL differences due to different water vapor content in the sampled air masses may also be responsible for the deviations similar to the case discussed in section 5 a.

\section{c. At 1736:09 UTC 14 June 2002}

On 14 June 2002, the DLR Falcon and DC-8 tracks crossed at $\sim 1736: 09$ UTC with a minimum distance of the footprints at a given time of $<0.3 \mathrm{~km}$. The flight tracks of both aircrafts in the vicinity of the meeting point are shown in Fig. 7. DLR DIAL data are not available at the meeting point but at a minimum distance of $\sim 1 \mathrm{~km}$ to the 1-min leg for which LASE data are available (Fig. 7). Internal quality checks of LASE showed that as a result of an operational discrepancy 

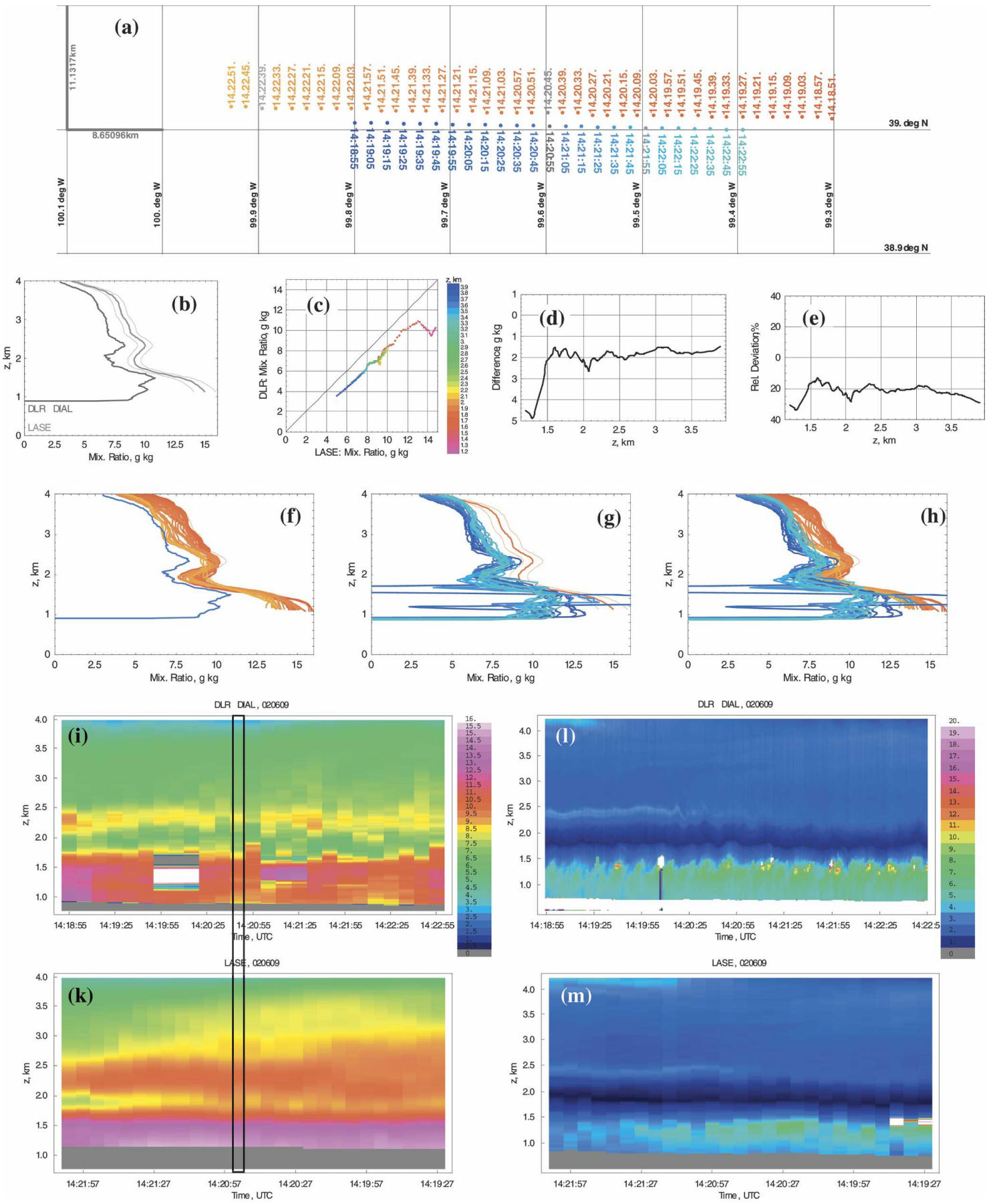

FIG. 6. Intercomparison of the water vapor mixing ratio measured with DLR DIAL and with LASE at 1420:50 UTC 9 Jun 2002. (a) Locations and measurement times in UTC where DLR DIAL data (blue to cyan) and LASE data (red to orange) were taken between $\sim 1418: 50$ and 1422:50 UTC 9 Jun 2002, time averaging window length of the LASE and DLR DIAL data is 1 min and $10 \mathrm{~s}$, respectively. Center times of the averaging windows are plotted. (b) Water vapor mixing ratio: LASE data at 1420:51 UTC (temporal resolution of $1 \mathrm{~min}$ and sliding average of $330 \mathrm{~m}$ ) and DLR DIAL data at 1420:45 UTC (temporal resolution of $10 \mathrm{~s}$ and effective vertical resolution of $195 \mathrm{~m}$ ); at this location and time the planes were closest to each other. Thin lines shown with the LASE profile at 1420:51 UTC mark the 6\% relative error estimated for the LASE data. The horizontal line at the bottom of the DLR DIAL profile is an artifact due to masking of the data. (c) Scatterplot of the water vapor data for heights ASL between 1.2 and $3.9 \mathrm{~km}$ (color coded). (d), (e) Absolute and relative differences of the data. (f)-(h) Measurement data before and after the time when the lidar footprints were closest [same temporal and spatial resolution, color coding as in (a)]. (i), (k) Contour plot of the water vapor data. The compared profiles are marked. (1), (m) Aerosol fields measured simultaneously with the water vapor data shown in (i), (k). Resolutions are 15 $\mathrm{m}$ and $1 \mathrm{~s}$ for the DLR DIAL data and $60 \mathrm{~m}$ and $6 \mathrm{~s}$ for the LASE data. The range-corrected backscatter data of DLR DIAL were scaled to show similar values like the aerosol backscatter ratio of LASE data. 
TABLE 2. Mean differences between LASE and DLR DIAL humidity data for the intercomparison at $\sim 1420: 51$ UTC 9 Jun 2002 (see Fig. 6) in the height intervals indicated.

\begin{tabular}{ccccc}
\hline \hline $\begin{array}{c}\text { Height } \\
\text { interval } \\
(\mathrm{km} \mathrm{ASL})\end{array}$ & $\begin{array}{c}\text { Differences } \\
(\mathrm{DLR}-\mathrm{LASE}) \\
\left(\mathrm{g} \mathrm{kg}^{-1}\right)\end{array}$ & $\begin{array}{c}\text { Difference } \\
(\mathrm{DLR}-\mathrm{LASE}) \\
(\%)\end{array}$ & $\begin{array}{c}\mathrm{RMS} \\
\left(\mathrm{g} \mathrm{kg}^{-1}\right)\end{array}$ & $\begin{array}{c}\mathrm{RMS} \\
(\%)\end{array}$ \\
\hline $1.3-1.8$ & -2.5 & -16 & 2.7 & 25 \\
$1.8-2.3$ & -2.1 & -21 & 2.1 & 25 \\
$2.3-2.8$ & -1.9 & -21 & 1.9 & 23 \\
$2.8-3.3$ & -1.7 & -24 & 1.7 & 22 \\
$3.3-3.8$ & -1.8 & -27 & 1.8 & 27 \\
$1.3-3.8$ & -2.0 & -25 & 2.1 & 25 \\
$1.2-3.9$ & -2.1 & -25 & 2.2 & 26 \\
\hline
\end{tabular}

during IHOP flights 10 (11 June) and 11 (14 June), the water vapor profiles derived from the LASE measurements throughout these flights had to be adjusted. The amount of this adjustment $(-13 \%)$ was determined by comparison with the closest water vapor intercomparisons on both flights, including seven SRL profiles and one sonde launched at the Homestead Profiling Site on flight 11 and three Lear dropsondes on flight 10. Thus, while comparisons between SRL and LASE intercomparisons had to be discarded for this day, LASE and DLR DIAL data are independent and it is interesting to compare these.

The variability of the water vapor field in this case is smaller as for the two previous DLR DIAL to LASE intercomparisons discussed (24 May and 9 June). Figures $7 \mathrm{~b}-\mathrm{e}$ show the average of four 1-s DLR DIAL water vapor profiles 1735:39-1735:42 UTC and the LASE profile centered at 1736:08 UTC as well as a scatterplot of the humidity data, absolute differences of the data and relative deviations. The results are summarized in Table 3.

The overall agreement of the data in the height range of $1.4-3.0 \mathrm{~km}$ ASL is very good:

$$
\overline{\operatorname{Bias}}_{\text {DLR-LASE,absolute }}=-0.30 \mathrm{~g} \mathrm{~kg}^{-1} \text {, }
$$

(DLR-DIAL drier)

$$
\begin{aligned}
\overline{\mathrm{Bias}}_{\text {DLR-LASE,relative }} & =-4.6 \%, \\
\overline{\mathrm{RMS}}_{\text {absolute }} & =0.61 \mathrm{~g} \mathrm{~kg}^{-1}, \text { and } \\
\overline{\mathrm{RMS}}_{\text {relative }} & =9.1 \% .
\end{aligned}
$$

\section{d. Summary of LASE to DLR DIAL intercomparisons}

Figure 8 summarizes the results of the two intercomparison cases for DLR DIAL and LASE data possible with the IHOP_2002 dataset. There is no clear height dependence of the differences and RMS deviation found for the two comparison cases discussed in sections $5 \mathrm{~b}$ and $5 \mathrm{c}$. Only the absolute value of the relative difference (in \%) increases with height in both cases. While the absolute value of the difference (in $\mathrm{g} \mathrm{kg}^{-1}$ ) decreases with height for 9 June, the height dependence is less dominant on 14 June. The RMS deviations show no clear trend with height, except for 9 June the absolute RMS deviation decreases with height. More intercomparison cases between DLR DIAL and LASE would be necessary to perform a statistical analysis and derive the bias between these two instruments directly. Unfortunately, the IHOP_2002 dataset does not provide these. So in the next section we compare the results of the two direct intercomparisons between DLR DIAL and LASE that were possible with the results of intercomparisons with the ground-based Raman lidar SRL (Part I). The comparison results with SRL are then used to derive the overall mean bias between all four lidars DLR DIAL, LASE, LEANDRE II, and SRL.

\section{Discussion of the results and conclusions}

Atmospheric effects play a very important role in the interpretation of the results. The effects are even stronger than for the ground-based-to-airborne lidar intercomparisons discussed in a companion paper (Part I). The sampling of different air masses by the lidar systems is an important issue here. These effects are caused mainly by horizontal averaging and are most severe for isolated crossing points or approaches of the flight tracks. If the flight tracks are not parallel, the sampled air masses differ to a larger extend than the minimum distances of the aircrafts suggest. For instance, the data of the LASE system were usually averaged over 1 min. During this time the DC- 8 aircraft, which carried this sensor, moved by $14-16 \mathrm{~km}$. Thus, in the worst case of rectangular crossing, data sampled at distances $>10 \mathrm{~km}$ are included in the comparison even in the case of zero minimum distance. In addition, there are temporal gaps between the times when the planes reach the crossing points. The profile-to-profile intercomparisons performed in this study show that these spatial and temporal differences of the sampled air masses cause significant difficulties for the validation efforts.

For DLR DIAL and LASE only three isolated profile-to-profile intercomparisons can be investigated, while for LEANDRE-II and DLR DIAL data of one formation flight is available, which we analyzed in detail. During the formation flight, the flight tracks did 

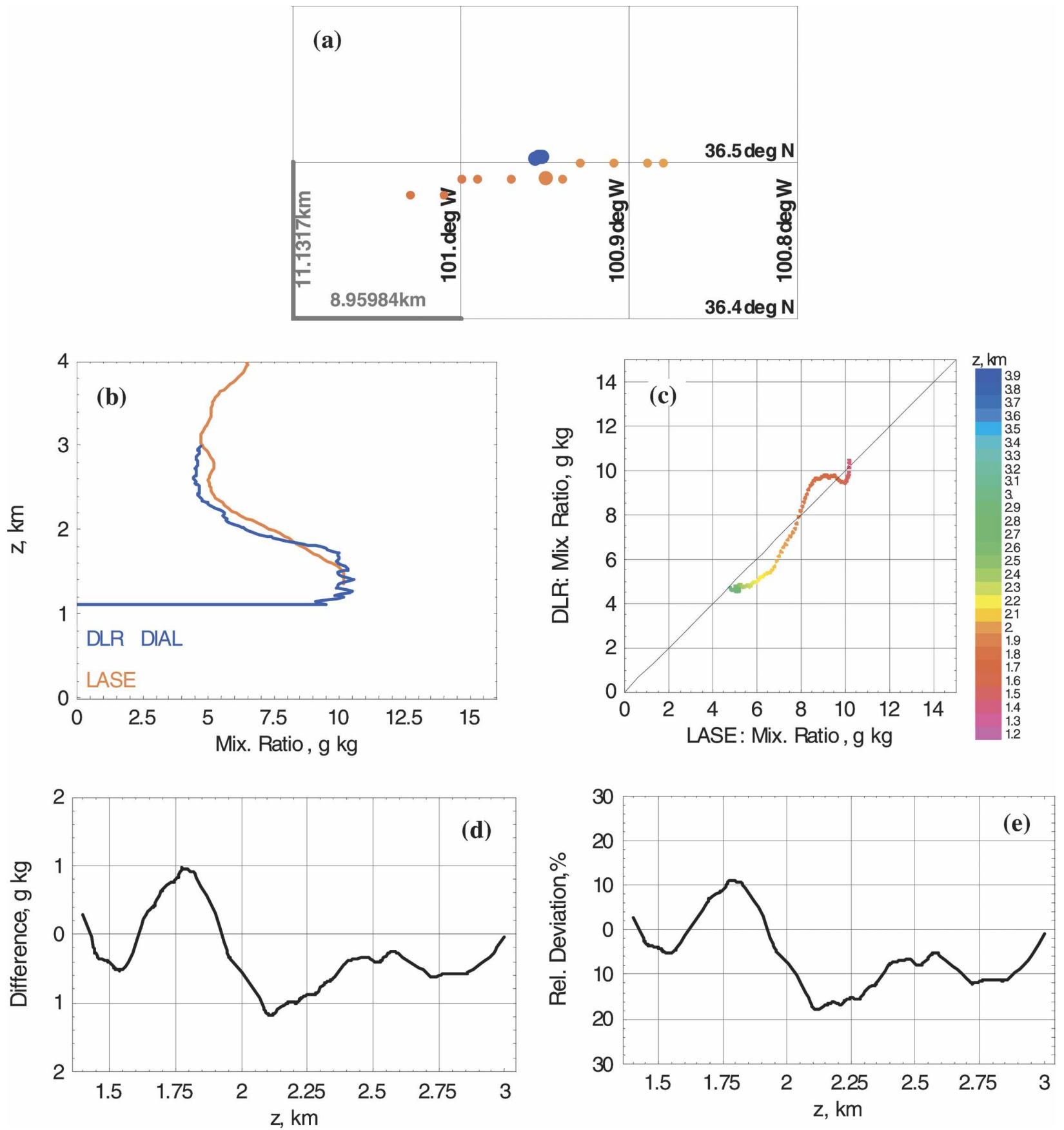

FIG. 7. Intercomparison of the water vapor mixing ratio measured with DLR DIAL and with LASE at $\sim 1736$ UTC 14 Jun 2002 . (a) Locations where DLR DIAL data and LASE data (red to orange) were taken. (b) The LASE water vapor profile is averaged over the flight track marked in reddish colors (60-s flight time centered at 1736:08 UTC). The DLR DIAL water vapor profiles are averaged over the flight track marked bluish (4-s flight time, 1735:39-1735:42 UTC). LASE data at 1736:20 UTC (temporal resolution of 1 min and sliding average of $330 \mathrm{~m}$ ) and DLR DIAL data at 1735:39-1735:42 UTC (temporal resolution of $4 \mathrm{~s}$ and effective vertical resolution of $195 \mathrm{~m}$ ). The horizontal line at the bottom of the DLR DIAL profile is an artifact due to masking of the data. (c) Scatterplot of the water vapor data for heights ASL between 1.4 and $3.0 \mathrm{~km}$ (color coded). (d), (e) Absolute and relative differences.

not coincide but were parallel with distances of $2-3 \mathrm{~km}$. Thus, it has to be noted that differences of the measured water vapor concentrations were not only due to statistical uncertainties of the data and/or systematic errors but also due to natural spatial inhomogeneities of the sampled atmospheric water vapor field.

For this formation flight, the average differences were 
TABLE 3. Mean differences between LASE and DLR DIAL humidity data for the intercomparison at $\sim 1736: 20$ UTC 14 Jun 2002 (see Fig. 7) in the height intervals indicated.

\begin{tabular}{ccccr}
\hline $\begin{array}{c}\text { Height } \\
\text { interval } \\
(\mathrm{km} \mathrm{ASL})\end{array}$ & $\begin{array}{c}\text { Difference } \\
(\mathrm{DLR}-\mathrm{LASE}) \\
\left(\mathrm{g} \mathrm{kg}^{-1}\right)\end{array}$ & $\begin{array}{c}\text { Difference } \\
(\mathrm{DLR}-\mathrm{LASE}) \\
(\%)\end{array}$ & $\begin{array}{c}\mathrm{RMS}^{-1} \\
\left(\mathrm{~g} \mathrm{~kg}^{-1}\right)\end{array}$ & $\begin{array}{r}\text { RMS } \\
(\%)\end{array}$ \\
\hline $1.4-1.8$ & 0.13 & -2.2 & 0.52 & 5.4 \\
$1.8-2.3$ & -0.45 & -2.5 & 0.82 & 11.9 \\
$2.3-2.8$ & -0.47 & -3.4 & 0.49 & 9.9 \\
$2.8-3.0$ & -0.44 & -9.2 & 0.46 & 9.6 \\
$1.4-3.0$ & -0.3 & -4.6 & 0.61 & 9.1 \\
\hline
\end{tabular}

$$
\begin{aligned}
\overline{\operatorname{Bias}}_{\text {LEA-DLR,absolute }}= & (-0.41 \pm 0.16) \mathrm{g} \mathrm{kg}^{-1}, \\
& (\text { LEANDRE II drier }) \\
\overline{\operatorname{Bias}}_{\text {LEA-DLR,relative }}= & (-7.9 \pm 3.1) \%, \\
\overline{\mathrm{RMS}}_{\text {absolute }}= & (0.87 \pm 0.18) \mathrm{g} \mathrm{kg}^{-1}, \quad \text { and } \\
\overline{\mathrm{RMS}}_{\text {relative }}= & (16.9 \pm 3.5) \%,
\end{aligned}
$$

for 54 intercomparisons of profiles with 10-s temporal average in the height range of 1.14-3.64 km above sea level.

Three profile-to-profile intercomparisons are available between LASE and the DLR DIAL. One of these cases (24 May 2002) has to be discarded due to clearly different water vapor field characteristics of the air masses sampled near a dryline. For the two remaining cases, we found that the data of one case (14 July 2002) show good agreement in the height range of $1.4-3.0 \mathrm{~km}$ ASL with

$$
\begin{aligned}
\overline{\operatorname{Bias}}_{\text {DLR-LASE,absolute }}= & -0.30 \mathrm{~g} \mathrm{~kg}^{-1}, \\
& \text { (DLR-DIAL drier) }
\end{aligned}
$$

$$
\begin{aligned}
\overline{\operatorname{Bias}}_{\text {DLR-LASE,relative }} & =-4.6 \%, \\
\overline{\mathrm{RMS}}_{\text {absolute }} & =0.61 \mathrm{~g} \mathrm{~kg}^{-1}, \text { and } \\
\overline{\mathrm{RMS}}_{\text {relative }} & =9.1 \% .
\end{aligned}
$$

In this case as a result of an operational discrepancy during IHOP flights 10 (11 June) and 11 (14 June), the water vapor profiles derived from the LASE measurements throughout these flights had to be adjusted by $-13 \%$. The amount of this adjustment was determined by comparison with the closest water vapor intercomparisons on both flights, including seven SRL profiles and one sonde launched at the Homestead Profiling Site on flight 11 and three Lear dropsondes on flight 10.

For the third case (9 June 2002), 25\% higher values
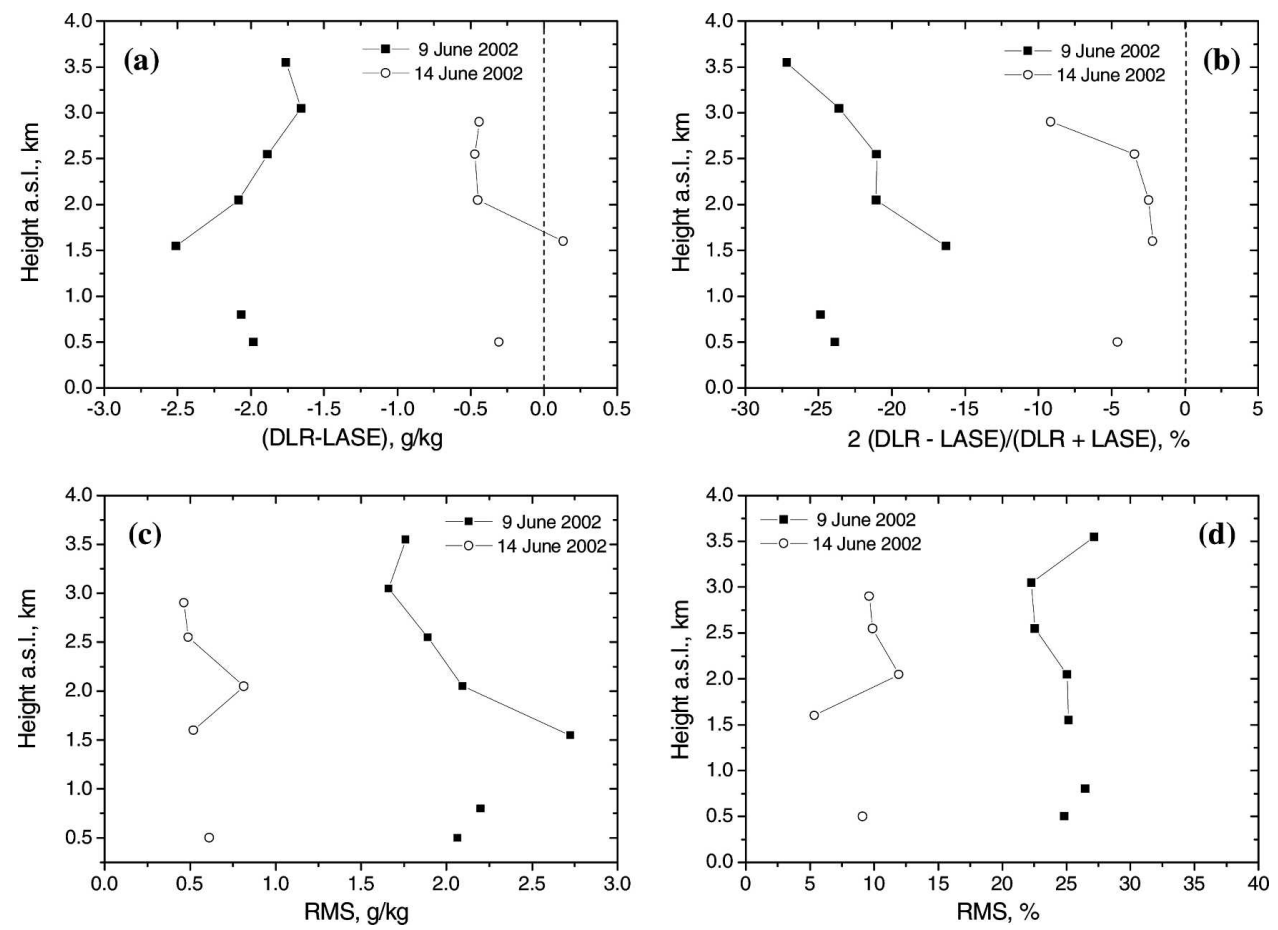

FIG. 8. Results for 500-m height intervals for the two intercomparisons of DLR DIAL and LASE. The data points plotted at $0.5-\mathrm{km}$ height ASL show the mean values for the height interval of $1.3-3.8 \mathrm{~km}$ ASL for 9 Jun 2002 and for 1.4-3.0 km for 14 Jun 2002; the data point at $0.8 \mathrm{~km}$ shows mean values for 1.2-3.9 $\mathrm{km}$ for 9 Jun 2002. (Same data as listed in Tables 2 and 3.) 
for the LASE data for the heights between 1.3 and 3.8 $\mathrm{km}$ above sea level were found. The reason for this unusually large difference could not be clarified yet.

Also comparisons between DLR DIAL, SRL, and LASE (Part I) indicated that DLR DIAL data are drier than LASE data. Mean biases between DLR DIAL and SRL and between SRL and LASE of $4.3 \% \pm 3.2 \%$ and $5.3 \% \pm 5.1 \%$, respectively (i.e., DLR DIAL data drier than SRL data drier than LASE data) were found. The bias of $-4.6 \%$ between DLR DIAL and LASE found for 14 July 2002 is well within the bias determined using SRL data that yields $-9.6 \% \pm 8.3 \%$ for DLR DIAL and LASE. The deviations found for the data of 9 July 2002 are not only larger than the mean including the standard deviations found in the SRL comparisons but also larger than any of the other single case deviations of one of the airborne DIAL systems and SRL. Thus, we conclude that for this case, either exceptional instrumental problems, which have not yet been identified, were present for one of the DIAL instruments or, indeed, the differences are largely due to natural humidity differences in the sampled air masses. In this context, it is noteworthy that the agreement of the LASE measurement and Falcon in situ measurement for the intercomparison on 9 June in $4.8 \mathrm{~km}$ ASL is excellent (i.e., $2.3 \%$ relative difference).

As discussed in (Part I), the relative bias is more appropriate than the absolute bias to describe deviations between lidar data because errors when humidity is derived from the lidar signals for both Raman lidar and DIAL scale with the amount of water vapor. The results of the intercomparisons are summarized in Fig. 9. In addition to the results of airborne-to-airborne intercomparisons, the results of intercomparisons with SRL (Part I) are also shown. With bias values of DLR DIAL, SRL, and LASE as determined in (Part I),

$$
\begin{aligned}
\overline{\operatorname{Bias}}_{\text {DLR,relative }} & =-4.6 \%, \\
\overline{\operatorname{Bias}}_{\text {SRL,relative }} & =-0.4 \%, \\
\overline{\operatorname{Bias}}_{\text {LASE,relative }} & =5.0 \%,
\end{aligned}
$$

we get for LEANDRE II an overall mean bias of

$$
\overline{\operatorname{Bias}}_{\text {LEA,relative }}=-12.5 \%
$$

using the result $\overline{\mathrm{Bias}}_{\mathrm{LEA}-\mathrm{DLR} \text {,relative }}=-7.9 \%$ of the formation flight (Fig. 9a) and $\overline{\mathrm{Bias}}_{\mathrm{LEA}-\text { DLR,relative }}=$

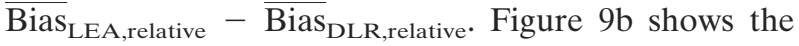
relative biases when the results of the formation flight of LEANDRE II and DLR DIAL are combined with the comparisons with SRL and new bias values are calculated in such a way that the sum of all biases equals zero:

$$
\begin{aligned}
& \overline{\text { Bias }}_{\text {DLR,relative }}^{*}+\overline{\text { Bias }}_{\text {LASE,relative }}^{*}+\overline{\text { Bias }}_{\text {LEA,relative }}^{*} \\
& +\overline{\text { Bias }}_{\text {SRL,relative }}^{*}=0 .
\end{aligned}
$$

Then we get

$$
\begin{aligned}
\overline{\operatorname{Bias}}_{\text {LEA,relative }}^{*} & =-9.3 \%, \\
\overline{\operatorname{Bias}}_{\text {DLR,relative }}^{*} & =-1.5 \%, \\
\overline{\text { Bias }}_{\text {SRL,relative }}^{*} & =2.7 \%, \text { and } \\
\overline{\operatorname{Bias}}_{\text {LASE,relative }}^{*} & =8.1 \% .
\end{aligned}
$$

(Slight deviations in the last digit are due to rounding of the results quoted here.)

\section{Summary}

During IHOP_2002, for the first time three airborne DIAL systems were operated simultaneously: the DLR DIAL, LEANDRE II of CNRS, and NASA's LASE. We performed an extensive analysis of the whole IHOP_2002 database and searched for cases in which comparisons between the data of these three instruments can be made. For this, we tentatively set a minimum distance of the laser footprints of less than $20 \mathrm{~km}$ as criteria. It turned out that the number of possible intercomparisons between the airborne DIAL systems was not large with the exception of one formation flight performed by DLR DIAL and LEANDRE II. Between DLR DIAL and LASE only two intercomparison cases were possible while intercomparisons between LEANDRE-II and LASE profiles cannot be performed due to a lack of temporal and spatial overlap.

In summary, despite some difficulties described above, we can conclude that the overall biases between the water vapor data of all three airborne lidar systems operated during IHOP_2002 are smaller than 10\% in the present stage of data evaluation, namely,

$$
\begin{aligned}
\overline{\operatorname{Bias}}_{\text {LEA,relative }}^{*} & =-9.3 \%, \\
\overline{\operatorname{Bias}}_{\text {DLR,relative }}^{*} & =-1.5 \%, \text { and } \\
\overline{\operatorname{Bias}}_{\text {LASE,relative }}^{*} & =8.1 \% .
\end{aligned}
$$

To assess these values, we also took the results of the intercomparisons of both DLR DIAL and LASE with SRL into account (Part I). Our results confirm the previous estimates of the instrumental accuracies for all the systems. We like to point out, however, that both LEANDRE II and DLR DIAL have not yet been evaluated as intensively as LASE and that these relative bias values should not be misunderstood as accuracies of the systems, which are the biases compared to the true value. In this context it has also to be noted 
(a)

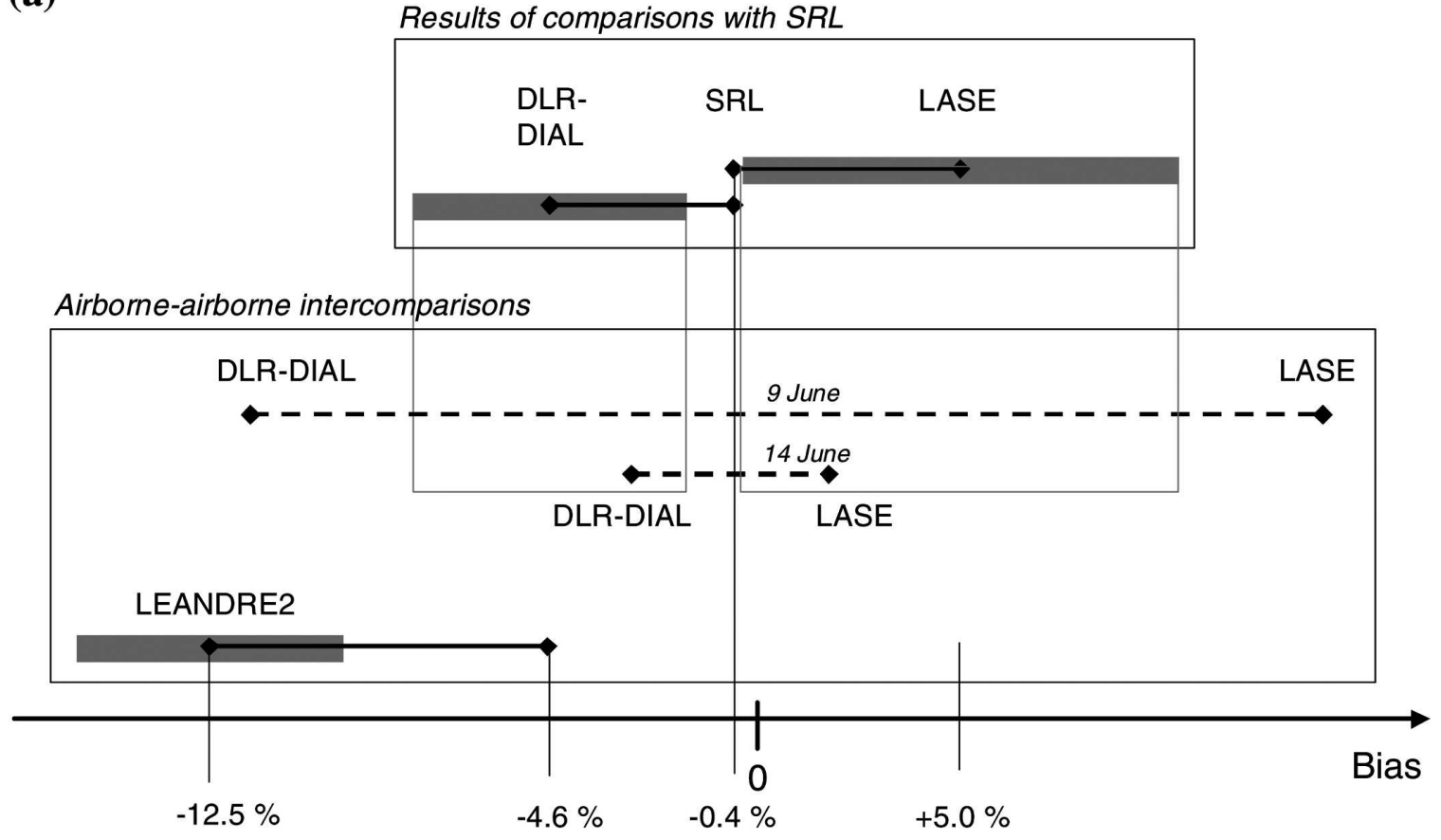

(b)

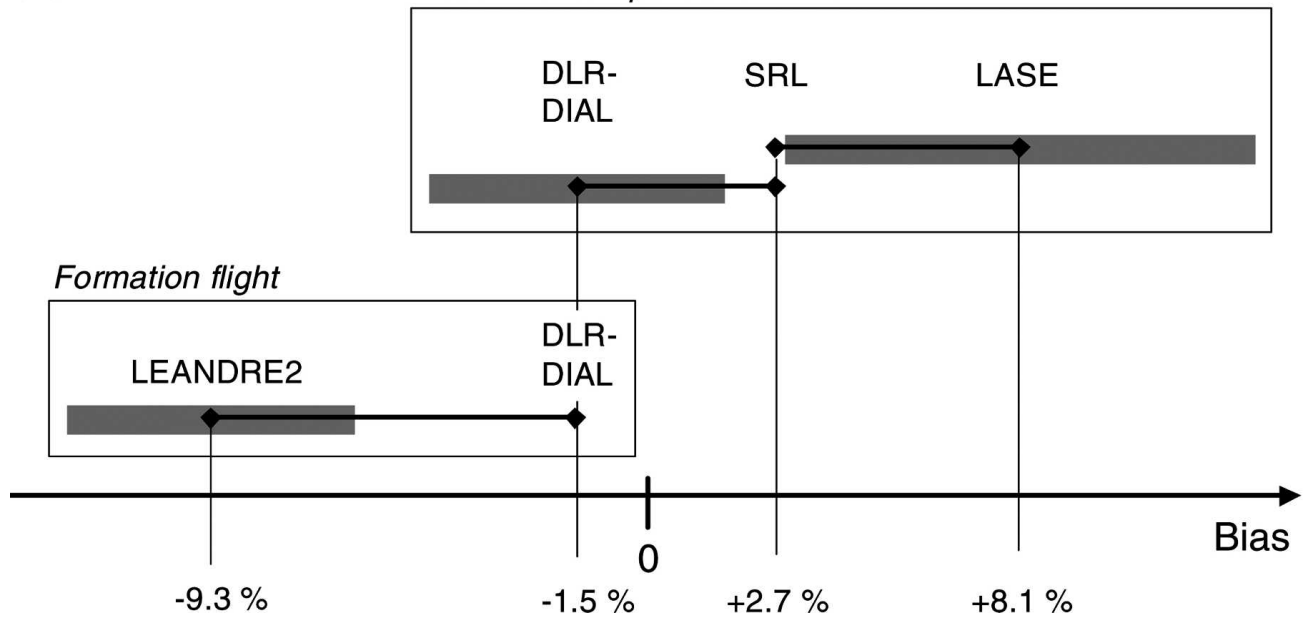

FIG. 9. Results of the intercomparisons. Horizontal bars with diamonds display the mutual relative bias between two water vapor sensors. Gray boxes show the $\pm 1 \sigma$ standard deviations of the intercomparisons. In addition to the results of airborne-to-airborne intercomparisons, the results of intercomparisons with SRL (Part I) are also shown. (a) Overall bias taking the comparisons with SRL as reference basis. We get an overall bias of $-12.5 \%$ for LEANDRE II with bias values of DLR DIAL, SRL, and LASE as determined in Part I. The bias values for the two isolated meeting points of LASE and DLR DIAL are also plotted for comparison (dashed). (b) Overall bias using the results of comparisons with SRL and the results of the formation flight of LEANDRE II and DLR DIAL and putting equal weight on the data reliability of each instrument. We get relative bias values of $-9.3 \%,-1.5 \%,+2.7 \%$, and $+8.1 \%$ for LEANDRE II, DLR DIAL, SRL, and LASE, respectively. (Slight deviations in the last digit are due to rounding.)

that the absorption cross-section parameters for the water vapor absorption line used by DLR DIAL were taken from the HITRAN_2001 database without further verification. More accurate spectroscopic measurements of this line are planned for the near future. As soon as these have been performed in the laboratory and a more accurate value of the absorption cross section is available, this will further reduce this kind of error source of DLR DIAL data.

This intercomparison study allows us to draw very 
important conclusions for future field campaigns. If airborne water vapor lidars are to be validated down to an accuracy of better than $5 \%$, it turned out that atmospheric variability of water vapor cannot be neglected down to scales of less than $1 \mathrm{~km}$. Therefore, dedicated flight patterns have to be applied for performing intercomparisons of airborne water vapor DIAL systems, that is, stacked formation flights along the same track (preferable are distances of the footprints $<0.5 \mathrm{~km}$ and temporal gaps $<30 \mathrm{~s}$ ) should be performed. Critical gaps in the temporal and spatial domain of course depend on atmospheric conditions (wind speed and homogeneity of the water vapor field) and resolution of the data products. Different speeds of aircrafts have to be taken into account in order to get the maximum overlap and minimum spatial distance along these stacked flights. It would be beneficial to repeat these flight patterns under different atmospheric conditions at different locations to get sophisticated statistics of the comparisons. Furthermore, it turned out to be very valuable to have in addition to airborne-to-airborne intercomparisons also continuously operating groundbased lidar systems as reference stations in the domain of interest-in contrast to, for example, radio soundings - as these have the advantage to perform measurements continuously in a fixed and well-defined column. Overpasses of the airborne instruments over these stations are very helpful to derive biases between the instruments and can be performed frequently for additional data validations.

Acknowledgments. This work was supported by the project "Measurement and Intercomparison of Active, Passive and In situ Sensors during the International $\mathrm{H}_{2} \mathrm{O}$ Project for the Verification of the Specifications of the WALES Experiment," sponsored by the ESA (Contract 16669/02/NL/FF). We highly acknowledge the support of many IHOP_2002 participants of this project, especially Tammy Weckwerth of NCAR and R. Michael Hardesty of NOAA.

\section{REFERENCES}

Behrendt, A., 2005: Temperature measurements with lidar. Lidar: Range-Resolved Optical Remote Sensing of the Atmosphere, C. Weitkamp, Ed., Springer Series in Optical Sciences, Vol. 102, Springer, 273-305.

, and V. Wulfmeyer, 2003: Combining water vapor DIAL and rotational Raman temperature lidar for humidity, temperature, and particle measurements with high resolution and accuracy. Proceedings of SPIE: Lidar Remote Sensing for Industry and Environment Monitoring IV, U. N. Singh, Ed., Vol. 5154, SPIE, 61-64.

, C. Kiemle, P. Di Girolamo, H.-S. Bauer, T. Schaberl, and V. Wulfmeyer, 2004a: Measurement and intercomparison of ac- tive, passive, and in-situ-sensors during the International $\mathrm{H}_{2} \mathrm{O}$ Project for the verification of the specifications of the WALES experiment. Second Tech. Note ESTEC Contract 16669/02/NL/FF, 115 pp.

,,,,----- , and $\_, 2004 \mathrm{~b}$ : Measurement and intercomparison of active, passive, and in-situ-sensors during the International $\mathrm{H}_{2} \mathrm{O}$ Project for the verification of the specifications of the WALES experiment. Final Rep. ESTEC Contract 16669/02/NL/FF, 56 pp.

_ , and Coauthors, 2007: Intercomparison of water vapor data measured with lidar during IHOP_2002. Part I: Airborne to ground-based lidar systems and comparisons with chilledmirror hygrometer radiosondes. J. Atmos. Oceanic Technol., 24, 3-21.

Bösenberg, J., 1998: Ground-based differential absorption lidar for water-vapor and temperature profiling. Appl. Opt., 37, 3845-3860.

Browell, E. V., and S. Ismail, 1995: First lidar measurements of water vapour and aerosols from a high-altitude aircraft. OSA Tech. Digest, Optical Remote Sensing of the Atmosphere Paper ThA4, 212-214.

—, and Coauthors, 1997: LASE validation experiment. Advances in Atmospheric Remote Sensing with Lidar, A. Ansmann et al., Eds., Springer Verlag, 289-295.

Bruneau, D., H. Cazeneuve, C. Loth, and J. Pelon, 1991: Doublepulse dual-wavelength alexandrite laser for atmospheric water vapor measurement. Appl. Opt., 30, 3930-3937.

—, P. Quaglia, C. Flamant, M. Meissonnier, and J. Pelon, 2001a: Airborne lidar LEANDRE II for water vapor profiling in the troposphere. I: System description. Appl. Opt., 40, 3450-3461.

—_ _ _ _ - and J. Pelon, 2001b: The air-borne lidar LEANDRE II for water vapor profiling in the troposphere. II. First results. Appl. Opt., 40, 3462-3475.

Couvreux, F., F. Guichard, J.-L. Redelsperger, C. Kiemle, V. Masson, J.-P. Lafore, and C. Flamant, 2005: Water vapour variability within a convective boundary layer assessed by Large Eddy Simulations and IHOP_2002 observations. Quart. J. Roy. Meteor. Soc., 131, 2665-2693.

Ehret, G., C. Kiemle, W. Renger, and G. Simmet, 1993: Airborne remote sensing of tropospheric water vapor using a near infrared DIAL system. Appl. Opt., 32, 4534-4551.

— K. P. Hoinka, J. Stein, A. Fix, C. Kiemle, and G. Poberaj, 1999: Low-stratospheric water vapor measured by an airborne DIAL. J. Geophys. Res., 104, 31 351-31 359.

European Space Agency, 2001: WALES-Water Vapour Lidar Experiment in Space. The five candidate Earth Explorer core missions, European Space Agency Assessment Rep. ESA SP1257(2), $91 \mathrm{pp}$.

_ 2 2004: WALES-Water Vapour Lidar Experiment in Space. The five candidate Earth Explorer core missions, European Space Agency Mission Selection Rep. ESA SP-1279(3), 51 pp.

Ferrare, R. A., and Coauthors, 2002: Characterization of upper tropospheric water vapour measurements during AFWEX using LASE. Proc. 21st ILRC, Lidar Remote Sensing in Atmospheric and Earth Sciences, Vol. I, Quebec, Canada, Defense R\&D Canada-Valcartier, 397-400.

—_, and Coauthors, 2004: Characterization of upper-troposphere water vapor measurements during AFWEX using LASE. J. Atmos. Oceanic Technol., 21, 1790-1808.

Gérard, É., D. G. H. Tan, L. Garand, V. Wulfmeyer, G. Ehret, and P. Di Girolamo, 2004: Major advances foreseen in hu- 
midity profiling from the Water Vapour Lidar Experiment in Space (WALES). Bull. Amer. Meteor. Soc., 85, 237-251.

Ismail, S., and E. V. Browell, 1989: Airborne and spaceborne lidar measurements of water vapor profiles: A sensitivity analysis. Appl. Opt., 28, 3603-3615.

Kiemle, C., G. Ehret, A. Giez, K. J. Davis, D. H. Lenschow, and S. P. Oncley, 1997: Estimation of boundary-layer humidity fluxes and statistics from airborne differential absorption lidar (DIAL). J. Geophys. Res., 102 (D24), 29 189-29 203.

Murphy, H., R. Wakimoto, C. Flamant, and D. Kingsmill, 2006: Dryline on 19 June 2002 during IHOP. Part I: Airborne Doppler and LEANDRE II analyses of the thin line structure and convection initiation. Mon. Wea. Rev., 134, 405-429.

Poberaj, G., A. Fix, A. Assioan, M. Wirth, C. Kiemle, and G. Ehret, 2002: Airborne all-solid-state DIAL for water vapor measurements in the tropopause region: System description and assessment of accuracy. Appl. Phys., 75B, 165-172.

Ponsardin, P. L., and E. V. Browell, 1997: Measurements of $\mathrm{H} 216 \mathrm{O}$ line strengths and air-induced broadenings and shifts in the 815-nm spectral regions. J. Mol. Spectrosc., 185, 58-70.

Schotland, R. M., 1966: Some observations of the vertical profile of water vapor by means of a ground based optical radar. Proc. Fourth Symp. on Remote Sensing of the Environment, Ann Arbor, MI, Environmental Research Institute of Michigan, University of Michigan, 273-283.
Warnecke, G., 1997: Meteorologie und Umwelt. Springer-Verlag, 354 pp.

Weckwerth, T. M., J. W. Wilson, and R. M. Wakimoto, 1996: Thermodynamic variability within the convective boundary layer due to horizontal convective rolls. Mon. Wea. Rev., 124, 769-784.

- and Coauthors, 2004: An overview of the International $\mathrm{H}_{2} \mathrm{O}$ Project (IHOP_2002) and some preliminary highlights. Bull. Amer. Meteor. Soc., 85, 253-277.

- H. Murphy, C. Flamant, C. Pettet, and R. Wakimoto, 2005: Along-frontal kinematic and moisture variability and the impact on convection initiation. Preprints, Second Symp. on Lidar Atmospheric Applications, San Diego, CA, Amer. Meteor. Soc., CD-ROM, 4.1.

Whiteman, D. N., and Coauthors, 2006a: Raman lidar measurements during the International $\mathrm{H}_{2} \mathrm{O}$ Project. Part I: Instrumentation and analysis techniques. J. Atmos. Oceanic Technol., 23, 157-169.

— - and Coauthors, 2006b: Raman lidar measurements during the International $\mathrm{H}_{2} \mathrm{O}$ Project. Part II: Case studies. J. Atmos. Oceanic Technol., 23, 170-183.

Wulfmeyer, V., and J. Bösenberg, 1998: Ground-based differential absorption lidar for water-vapor profiling: Assessment of accuracy, resolution, and meteorological applications. Appl. Opt., 37, 3825-3844. 